\title{
Characterization of Seasonal Pharmacokinetic Variability in Woodchucks ${ }^{\circledR}$
}

\author{
Jim Zheng, Scott Balsitis, Rex Santos, Bill J. Smith, and Raju Subramanian \\ Gilead Sciences, Inc., Foster City, California
}

Received June 16, 2020; accepted August 24, 2020

\begin{abstract}
The eastern woodchuck (Marmota monax) is a hibernating species extensively used as an in vivo efficacy model for chronic human hepatitis B virus infection. Under laboratory conditions, woodchucks develop a pseudohibernation condition; thus, the pharmacokinetics (PK) of small-molecule therapeutics may be affected by the seasonal change. The seasonal PK of four probe compounds were characterized over 12 months in seven male and nine female laboratorymaintained woodchucks. These compounds were selected to study changes in oxidative metabolism [antipyrine (AP)], glucuronidation [raltegravir (RTG)], renal clearance [lamivudine (3TC)], and hepatic function [indocyanine green (ICG)]. Seasonal changes in physiologic parameters and PK were determined. Seasonal body weight increases were $\geq 30 \%$. Seasonal changes in body temperature and heart rate were $<10 \%$. The mean AP exposure remained unchanged from April to August 2017, followed by a significant increase ( $\geq 1.0$ fold) from August to December and subsequent decrease to baseline at the end of study. A similar trend was observed in RTG and 3TC exposures. The ICG exposure remained unchanged. No significant sex difference in PK was observed, although female
\end{abstract}

woodchucks appeared to be less susceptible to seasonal PK and body weight changes. Significant seasonal PK changes for AP, RTG, and 3TC indicate decreases in oxidative metabolism, phase II glucuronidation, and renal clearance during pseudohibernation. The lack of seasonal change in ICG exposure suggests there are no significant changes in hepatic function. This information can be used to optimize the scheduling of woodchuck studies to avoid seasonally driven variation in drug PK.

\section{SIGNIFICANCE STATEMENT}

Woodchuck is a hibernating species and is commonly used as a nonclinical model of hepatitis $B$ infection. Investigation of seasonal PK changes is perhaps of greater interest to pharmaceutical industry scientists, who use the woodchuck model to optimize the scheduling of woodchuck studies to avoid seasonally driven variation in drug PK and/or toxicity. This information is also valuable to drug metabolism and veterinary scientists in understanding woodchuck's seasonal metabolism and behavior under the pseudohibernation condition.

\section{Introduction}

Despite the availability of an effective vaccine for the prevention of HBV infection, approximately 240 million individuals are chronically infected with $\mathrm{HBV}$, and over half a million people are estimated to die each year as a result of liver diseases associated with chronic hepatitis B (CHB), primarily due to liver diseases such as cirrhosis and hepatocellular carcinoma (World Health Organization) (https://www.who.int/ news-room/fact-sheets/detail/hepatitis-b). Approved treatment of CHB includes nucleos $(\mathrm{t})$ ide analogs as well as interferon- $\alpha$. These therapies repress viral replication and improve long-term outcome, but cure is rarely achieved. Consequently, there is an urgent need for new therapies that induce durable immune control, i.e., a functional cure, of HBV.

The woodchuck model of chronic hepadnavirus infection is indispensable in developing therapeutic strategies able to finally cure chronic HBV infection (Roggendorf and Tolle, 1995; Menne and

This research was funded by Gilead Sciences, Inc.

All authors are current employees of Gilead Sciences and declare no competing interest.

https://doi.org/10.1124/dmd.120.000140.

S This article has supplemental material available at dmd.aspetjournals.org.
Cote, 2007; Dandri and Petersen, 2017). The eastern woodchuck (Marmota monax), also known as the groundhog, can be naturally infected with woodchuck hepatitis virus (WHV), a hepadnavirus closely related to human HBV. The woodchuck model of CHB displays many characteristics of human disease and has provided a well characterized mammalian model for the preclinical evaluation of most antiviral drugs now in use for treatment of chronic HBV infection (Rajagopalan et al., 1996; Genovesi et al., 1998; Mason et al., 1998; Dandri et al., 2000; Korba et al., 2000; Bryant et al., 2001; Menne et al., 2005). Most recently, this model was used to evaluate the antiviral efficacy of various novel immunomodulatory agents, including the toll-like receptor 7 agonist vesatolimod (GS-9620) and the toll-like receptor 8 agonist selgantolimod (GS-9688) (Menne et al., 2015; Paulsen et al., 2015; Daffis et al., 2017, 2020; Mackman et al., 2020).

The eastern woodchuck is a hibernating species that undergoes large seasonal variations in metabolic state. Reduction in renal clearance and decrease in plasma atrial natriuretic factor were reported in hibernating marmots (Marmota flaviventris), a closely related species (Zatzman and South, 1972; Zatzman and Thornhill, 1989), and the hibernating 13-lined ground squirrel (Citellus tridecemlineatus) (Hong, 1957).

ABBREVIATIONS: AP, antipyrine; $\mathrm{AUC}_{0-24 \mathrm{~h}}$, area under time-concentration curve from time 0 to 24 hours; $\mathrm{AUC}_{\text {inf }}$, area under time-concentration curve from time 0 to infinity; BPM, beats per minute; CHB, chronic hepatitis B; CL, clearance; HBV, hepatitis B virus; ICG, indocyanine green; PK, pharmacokinetics; RTG, raltegravir; $t_{1 / 2}$, terminal half-life; $3 \mathrm{TC}$, lamivudine; $\mathrm{V}_{\mathrm{ss}}$, steady-state volume of distribution; WHV, woodchuck hepatitis virus. 
TABLE 1

Summary of structure and disposition pathways of the four probe compounds

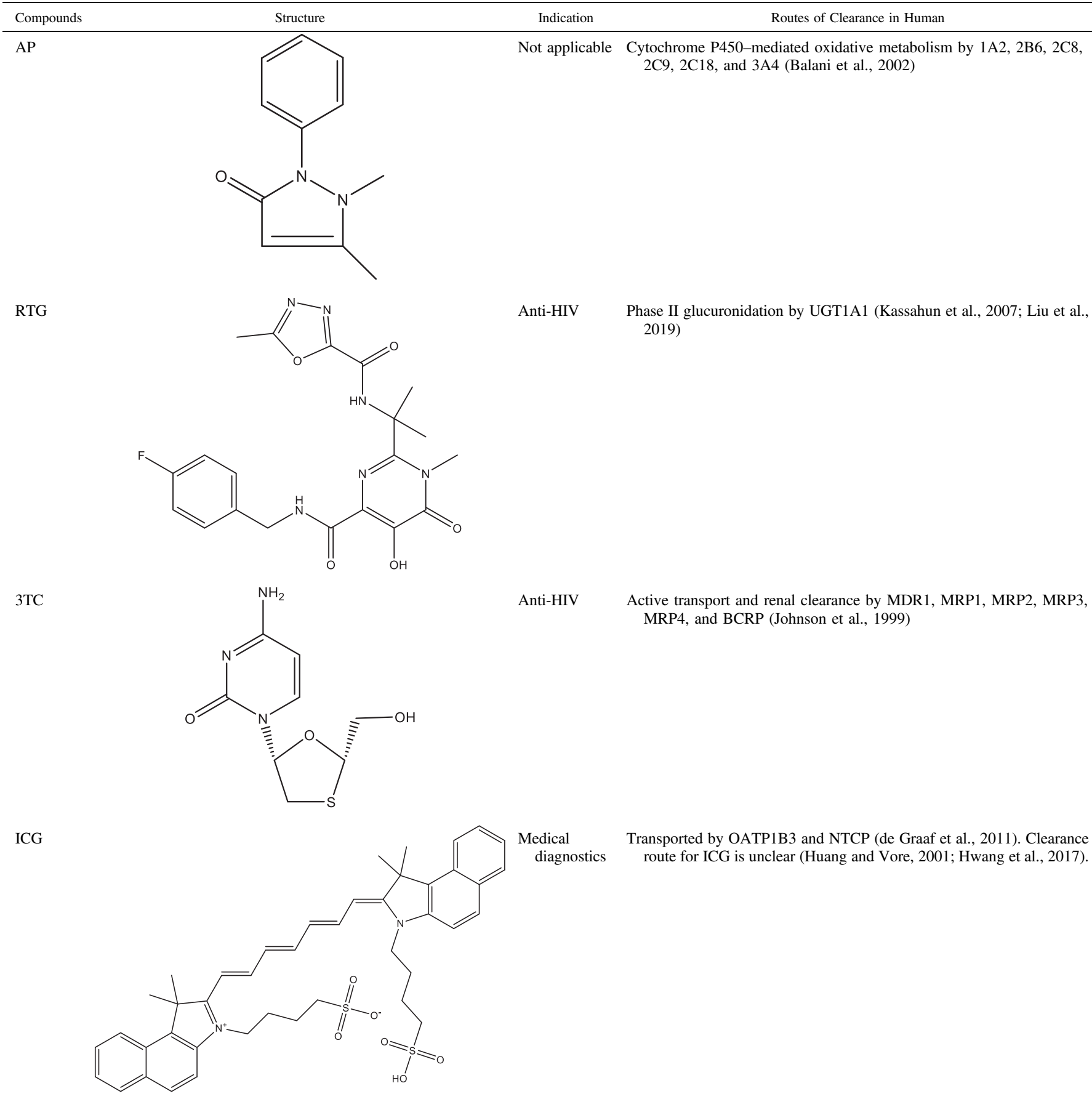

BCRP, breast cancer resistance protein; HIV, human immunodeficiency virus; MDR1, multidrug resistance mutation 1; MRP, multidrug resistance-associated protein; NTCP, sodium taurocholate cotransporting polypeptide; OATP1B3, organic anion transporter family 1 member B3; UGT1A1, UDP (uridine diphosphate) glucuronosyltransferase family 1 member A1.

In addition, seasonal changes in endocannabinoid concentrations between active and hibernating marmots were observed (Mulawa et al., 2018).

Under laboratory conditions, woodchucks develop a pseudohibernation condition during the winter. On the other hand, treatment duration utilizing the woodchuck model for HBV can last multiple weeks, depending on the treatment used, which makes it likely that these studies could overlap with the pseudohibernation period. This raises the possibility that small-molecule therapeutics administered to woodchucks at different times of year will have differences in PK and metabolism and therefore potential differences in on- and off-target effects.

Data describing the potential seasonal changes in metabolism and PK are scarce, especially if animals develop a pseudohibernation condition during winter. This report presents the characterization of seasonal PK changes of four probe compounds dosed intravenously once every 
TABLE 2

A snapshot of the seasonal woodchuck PK study design

\begin{tabular}{|c|c|}
\hline Dose Frequency & $\begin{array}{l}\text { Once Every } 4 \text { wk from March 16, 2017, to April 18, } \\
\qquad 2018\end{array}$ \\
\hline Dose route & $\begin{array}{l}\text { Intravenous bolus administration via 2-min slow } \\
\text { push }\end{array}$ \\
\hline $\begin{array}{l}\text { Dose volume, concentration, } \\
\text { amount }\end{array}$ & $\begin{array}{l}1 \mathrm{ml} / \mathrm{kg}, 0.5 \mathrm{mg} / \mathrm{ml} \text {, cassette dose at } 0.5 \mathrm{mg} / \mathrm{kg} \\
\text { for each compound }\end{array}$ \\
\hline Formulation vehicle & $\begin{array}{l}10 \% \text { ethanol, } 10 \% \text { polyethylene glycol } 300 \text {, and } \\
80 \% \text { water }\end{array}$ \\
\hline Fasted/fed & Nonfasted \\
\hline Anesthetic agents & Ketamine/xylazine combination \\
\hline Number of animals & Seven males, nine females \\
\hline Sample matrix & Plasma \\
\hline Time points & 5 and $10 \mathrm{~min}$ and $1,2,4,8$, and $24 \mathrm{~h}$ \\
\hline Physiologic parameters & Body weight, body temperature, and heart rate \\
\hline Laboratory conditions & $\begin{array}{l}\text { Steady room temperature, mimicking external } \\
\text { seasonal light cycle }\end{array}$ \\
\hline
\end{tabular}

4 weeks over 12 months in male and female woodchucks. Using the exposures of the parent compounds as markers, these compounds were selected to study specific changes in oxidative metabolism with AP
(Balani et al., 2002), phase II glucuronidation with RTG (Kassahun et al., 2007; Liu et al., 2019), renal clearance with 3TC (Johnson et al., 1999), and hepatic function with ICG (Cooke et al., 1963; Huang and Vore, 2001; de Graaf et al., 2011; Hwang et al., 2017).

\section{Materials and Methods}

Materials. AP, RTG, 3TC, and ICG were purchased from Sigma-Aldrich (St. Louis, MO) or VWR International (West Chester, PA) and were of highperformance liquid chromatography or analytic grade. Structure of the probe compounds and their disposition pathways are summarized in Table 1.

Woodchucks. At the initiation of the study, a total of 16 juvenile woodchucks (M. monax), seven males and nine females, were used. All animals used in these studies were born in the laboratory facility of Northeastern Wildlife, Inc. (Harrison, ID), in the spring of 2016 and inoculated with WHV neonatally (3-5 days of age) by subcutaneous administration of $10^{7}$ genome equivalents per milliliter WHV (strain WH7P2A) but had naturally cleared the infection by quantifying their serum levels of woodchuck hepatitis surface antigen throughout the infection phase. The neonatal WHV inoculation is a standard procedure in preparing WHV chronically infected woodchucks for the study of HBV cure. Woodchucks were about 1 year old at the initiation of the study. Throughout the study duration, animals were housed in floor pens containing cedar or aspen wood
A

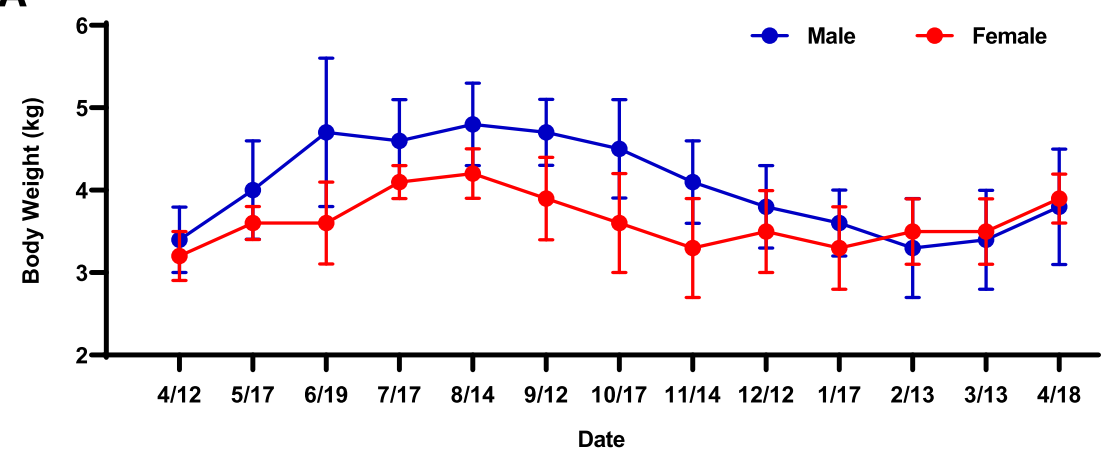

B

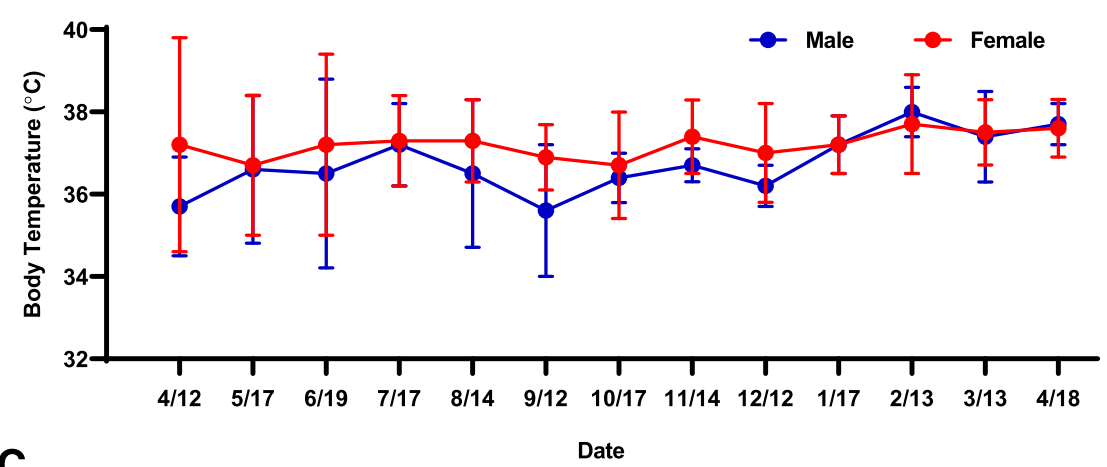

C

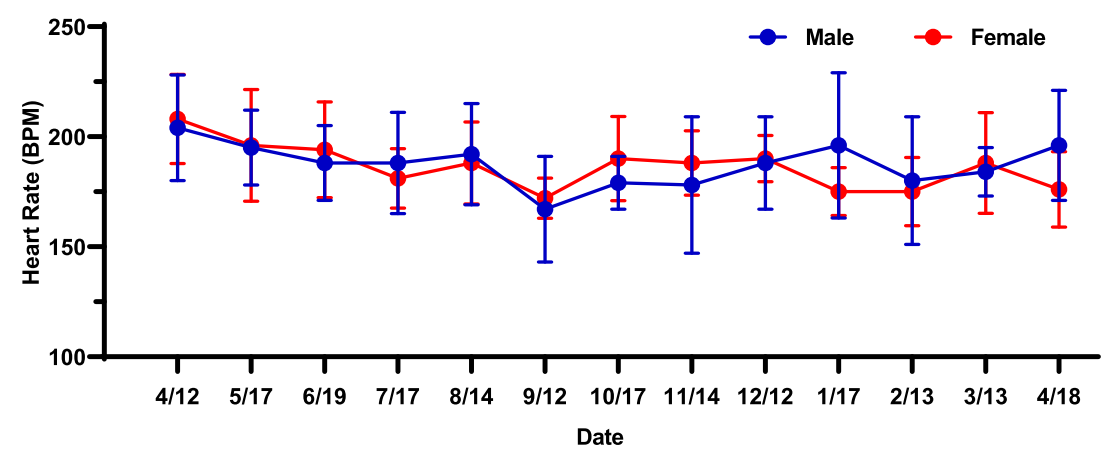

Fig. 1. Seasonal changes of physiologic parameters from April 12, 2017, to April 18, 2018: (A) body weight; (B) body temperature; (C) heart rate. Dates were plotted from April 12, 2017, to April 18, 2018. The body weight increases from April 12, 2017, to August 14, 2017, were statistically significant for both male $(P<0.0001)$ and female $(P<$ 0.0001 ) woodchucks, even though the magnitude of change in males was greater than that in females. No significant changes in body temperature and heart rate were observed throughout the study duration for either male or female woodchucks. Statistical analysis was performed using an unpaired, twotailed, parametric $t$ test method (mean \pm S.D., $n=6$ or 7 for male, $n=7$ or 9 for female; three woodchucks died during the study). 
A

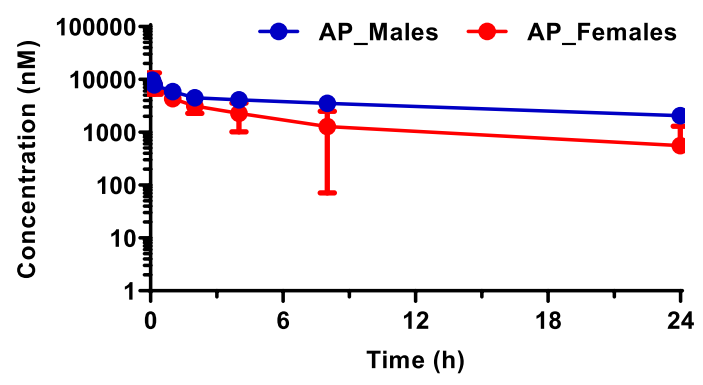

C

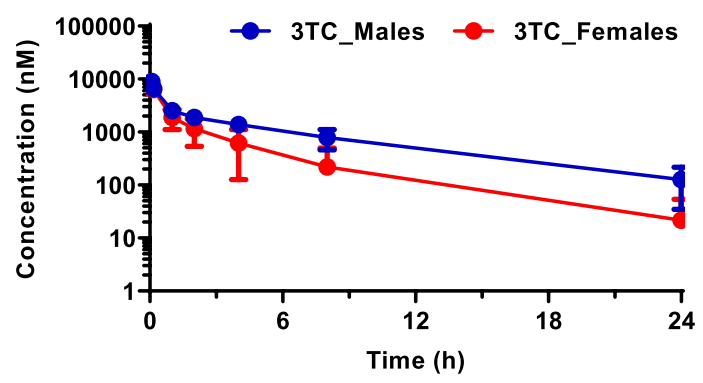

B

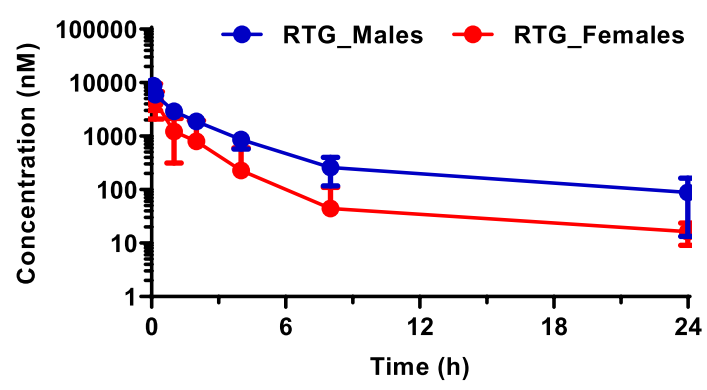

D

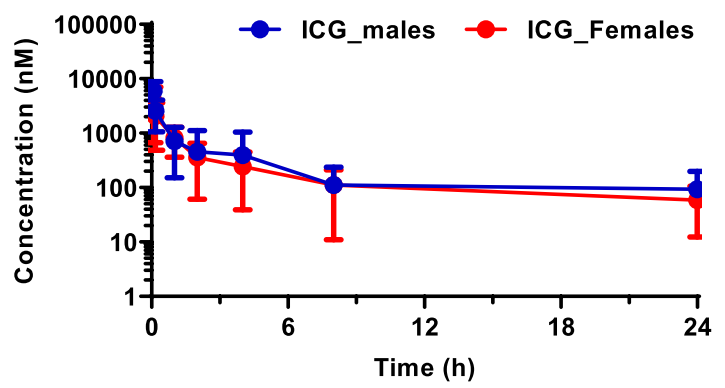

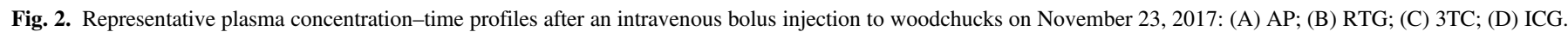

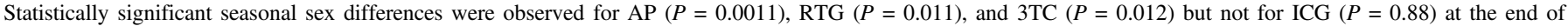
November. Statistical analysis was performed using an unpaired, two-tailed, parametric $t$ test method (mean \pm S.D., $n=6$ for male, $n=7$ for female).

shavings, maintained under daily 12-hour light/dark cycles, and fed with rabbit chow [Purina; $16 \%$ crude protein ( $\geq 18 \%$ for pups and pregnant animals), $2 \%$ crude fat, $\sim 15 \%$ crude fiber, vitamin A (4500 IU), $1 \%$ calcium, and $0.5 \%$ phosphate]. Animals were not fasted prior to treatment.

Seasonal Single-Dose PK Studies in Woodchucks. The animal protocol and all procedures involving woodchucks were reviewed and approved by the Northeastern Wildlife institutional animal care and use committee and adhered to the national guidelines of the Animal Welfare Act, the Guide for the Care and Use of Laboratory Animals, and the American Veterinary Medical Association. A prestudy was conducted on March 16, 2017, to ensure animal safety and to safeguard any potential adverse event due to a four-drug cocktail coadministration. In that study, five separate vials of formulated solution were provided, including four vials containing the individual compounds formulated separately and a fifth vial with all four compounds coformulated into a single formulation. The four compounds, AP, RTG, 3TC, and ICG, were either individually formulated or coformulated as a solution, each at a dose concentration of $0.5 \mathrm{mg} / \mathrm{ml}$ and a dose volume of $1 \mathrm{ml} / \mathrm{kg}$ in $10 \%$ ethanol, $10 \%$ polyethylene glycol 300, and $80 \%$ water. The formulated solution was administered by a 2 -minute intravenous slow bolus injection via an indwelling catheter in a cephalic vein at a dose of $0.5 \mathrm{mg} / \mathrm{kg}$ for each compound. The formulations were provided in $25-\mathrm{ml}$ single-use sterile vials, refrigerated at $2-8{ }^{\circ} \mathrm{C}$, and protected from light. Animals were divided into five groups of $n=3$ for each. ICG, RTG, 3TC, AP, and the four-compound coformulation were administered to woodchucks in groups $1-5$, respectively.

The main study, involving a monthly administration of the four-drug cocktail, occurred from April 12, 2017, to April 18, 2018. A snapshot of the PK study is summarized in Table 2. A coformulated cocktail of all four compounds consisted of each compound formulated at the same dose, volume, dosing concentration, and vehicle, as described above. The cocktail was provided in $75-\mathrm{ml}$ single-use sterile vials, refrigerated at $2-8^{\circ} \mathrm{C}$, and protected from light. One vial was shipped to Northeastern Wildlife, Inc., for each monthly dosing.

The monthly dosing was scheduled to occur once every 4 weeks. However, each dosing day could be potentially moved by up to 4 days before or after the date to accommodate scheduling conflicts. Body weight, body temperature, and heart rate were measured in each animal prior to dosing each month. Heart rate was determined prior to the induction of anesthesia for blood collections using a ketamine/xylazine combination approach. $\mathrm{K}_{2}$ EDTA was used for PK and hematology sample collection. No anticoagulant was used for samples collected for clinical chemistry. Roughly $1.0 \mathrm{ml}$ of blood was collected for complete blood count and hematology. PK samples were collected at 5 and 10 minutes and 1, 2, 4, 8 , and 24 hours postdose. Blood for PK $(0.5 \mathrm{ml})$ and hematology $(1.0 \mathrm{ml})$ was protected from light and maintained on wet ice in chilled cryoracks or at approximately $5^{\circ} \mathrm{C}$ prior to centrifugation to obtain plasma. Centrifugation began within 1 hour of collection. Individual plasma samples were harvested, placed into 96-well tubes, and maintained on dry ice prior to storage at approximately $-70^{\circ} \mathrm{C}$. Samples for clinical chemistry, complete blood count, and hematology were handled according to the contract research organization standard operating procedures. The clinical pathology data were included in the final study report as an appendix for informational purposes. Urine samples were not collected, to minimize disruption of the animals.

Tolerability was assessed on-site via in-life parameters including daily visual observation of the woodchucks, as well as body weight and body temperature. Clinical pathology was assessed by analyzing serum chemistry, hematology, and coagulation samples at Cornell University, Animal Health Diagnostic Center (Ithaca, NY).

Bioanalytical and PK Analysis. Plasma samples were protected from light and stored at $-20^{\circ} \mathrm{C}$ until they were shipped to Charles River Laboratories (Worcester, MA) for bioanalysis. Plasma concentrations of all four administered compounds were quantified by liquid chromatography-tandem mass spectrometry methods. The representative bioanalytical methods and assay performance are detailed in Supplemental Tables 1 and 2. Analyst software (AB Sciex, Framingham, MA) was used for data acquisition and chromatographic integration. Analyst data were exported to Watson LIMS software version 7.4.1 (Thermo Fisher Scientific, Waltham, MA) for regression analysis, concentration calculations, and descriptive statistics.

Pharmacokinetic parameters, including area under the plasma concentration-time curve from time 0 to 24 hours $\left(\mathrm{AUC}_{0-24 \mathrm{~h}}\right)$, area under the plasma concentration-time curve from time 0 to infinity $\left(\mathrm{AUC}_{\mathrm{inf}}\right), C_{\mathrm{max}}$, terminal half-life $\left(t_{1 / 2}\right)$, steady-state volume of distribution $\left(\mathrm{V}_{\mathrm{ss}}\right)$, and clearance $(\mathrm{CL})$, were determined by noncompartmental analysis using Phoenix WinNonlin 6.4 (Pharsight Corporation, Princeton, NJ). 


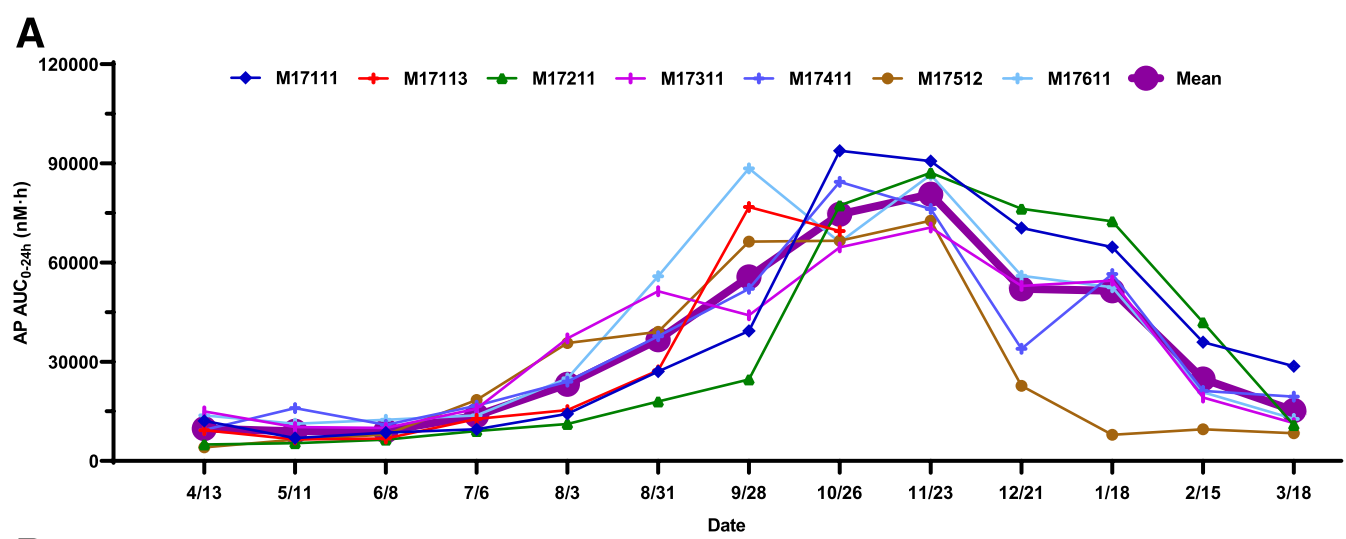

B

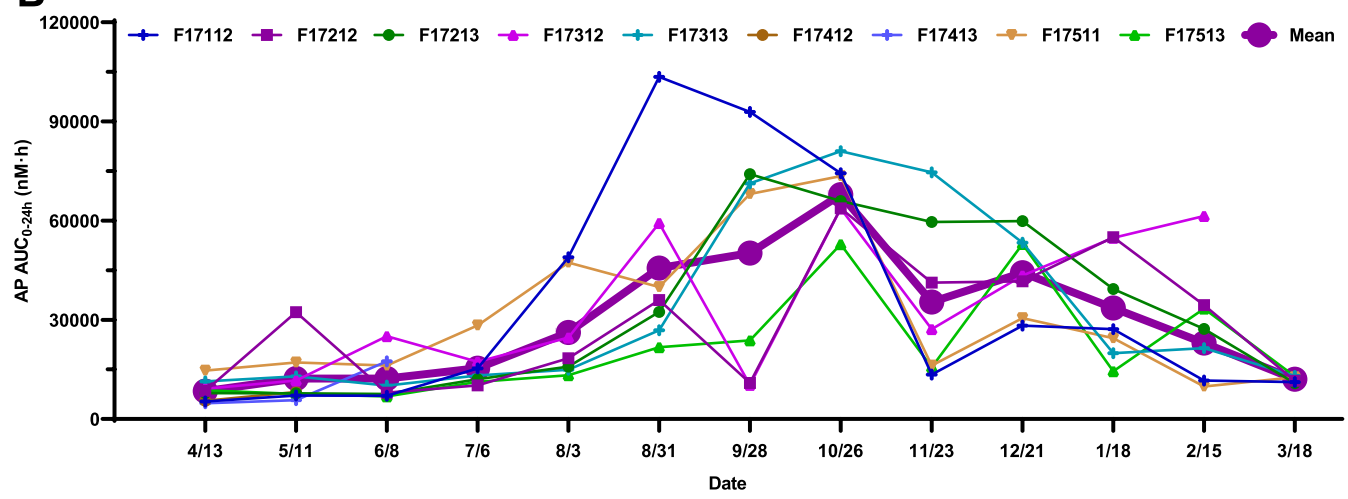

Fig. 3. Individual and mean seasonal $\mathrm{AUC}_{0-24 \mathrm{~h}}$ changes of AP: (A) male; (B) female. Dates were plotted from April 13, 2017, to March 18, 2018. The AUC $0-24 \mathrm{~h}$ of $\mathrm{AP}$ remained relatively unchanged from April to August and then gradually increased from August to the end of November, reaching the maximum by the end of November and subsequently returning to baseline in March of the following year. A similar trend was observed in female woodchucks, but the peak exposure was reached at the end of October. The exposure increases from May to November in both male and female woodchucks were statistically significant. The magnitude of exposure change was less pronounced in females than in males. Statistical analysis was performed using an unpaired, two-tailed, parametric $t$ test method. Three woodchucks died during the study.

Three woodchucks died during the study for reasons that were judged by the veterinarian to be unrelated to the study drugs. Details of the clinical observations were summarized in Supplemental Materials.

Statistical Analysis. Student's $t$ test was performed with GraphPad Prism version 7.03 (GraphPad Software, San Diego, CA) using an unpaired, two-tailed, parametric method with 95\% confidence level assuming same S.D. for both populations. $P$ values less than 0.05 were considered statistically significant. At least two values were required to calculate the mean. At least three values were required to report S.D.

\section{Results}

Woodchuck Baseline Characteristics. The mean body weight was 3.3 (S.D. 0.4) kg (range 2.6-3.9 kg). The mean (S.D.) body temperature was $37.7^{\circ} \mathrm{C}(0.9)$ (range $37.0-38.7^{\circ} \mathrm{C}$ ). The mean heart rate under restrained condition was 244 (50) beats per minute (BPM) (range 126-312 BPM). The mean heart rate under anesthesia condition was 130 (21) BPM (range 105-156 BPM). All animals had $\gamma$-glutamyl transferase $<10$ international units per liter at the time of study initiation and were in good overall health.

Seasonal Changes of Physiologic Parameters. Seasonal changes in body weight, body temperature, and heart rate for both male and female woodchucks from March 16, 2017, to April 18, 2018, are plotted in Fig. 1. A trend of weight gain from April to June, reaching a plateau from June to October and back to baseline on January, was observed in male woodchucks. The body weight trend in female woodchucks was slightly different: a slow increase was observed from April to August, reaching a peak in August, followed by a decline to baseline in November (Fig. 1A). The body weight increases from April 12, 2017, to August 14,
2017, were statistically significant for both male $(P<0.0001)$ and female $(P<0.0001)$ woodchucks, even though the magnitude of change in males $(42 \% \pm 12 \%)$ was greater than that in females $(30 \% \pm 18 \%)$. No significant changes $(<10 \%)$ in body temperature and heart rate were observed throughout the study duration for either male or female woodchucks maintained under laboratory conditions (Fig. 1, B and C).

Seasonal Changes of PK Parameters. Representative plasma concentration-time profiles after an intravenous coinjection of AP, RTG, 3TC, and ICG in woodchucks on November 23, 2017, are shown in Fig. 2. Seasonal $\mathrm{AUC}_{0-24 \mathrm{~h}}$ changes from April 13, 2017, to March 18, 2018, are plotted in Figs. 3-6. Tabulated summary of the $\mathrm{AUC}_{0-24 \mathrm{~h}}$ values of AP, RTG, 3TC, ICG and plots of statistical analysis from the prestudy and the seasonal PK study are available in Supplemental Materials (Supplemental Fig. 1; Supplemental Table 3). Additional PK parameters, such as $\mathrm{AUC}_{\mathrm{inf}}, C_{\mathrm{max}}, t_{1 / 2}, \mathrm{~V}_{\mathrm{ss}}$, and CL, from prestudy and representative PK data from May 11 and November 23, 2017, are summarized in Supplemental Table 3 and plotted in Fig. 9, respectively.

The prestudy results (Supplemental Table 3) did not show any significant drug-drug interactions when comparing the corresponding $\mathrm{AUC}_{0-24 \mathrm{~h}}$ values of $\mathrm{AP}, \mathrm{RTG}, 3 \mathrm{TC}$, and ICG after the intravenous administration of individual formulation versus fourdrug coformulation.

The $\mathrm{AUC}_{0-24 \mathrm{~h}}$ of $\mathrm{AP}$ remained relatively unchanged from April to August and then gradually increased from August to the end of November $(3.1 \pm 2.4$-fold increase in males and $1.0 \pm 1.8$-fold increase in females), reaching the maximum by the end of November, and subsequently returned to baseline in March of the following year 
A

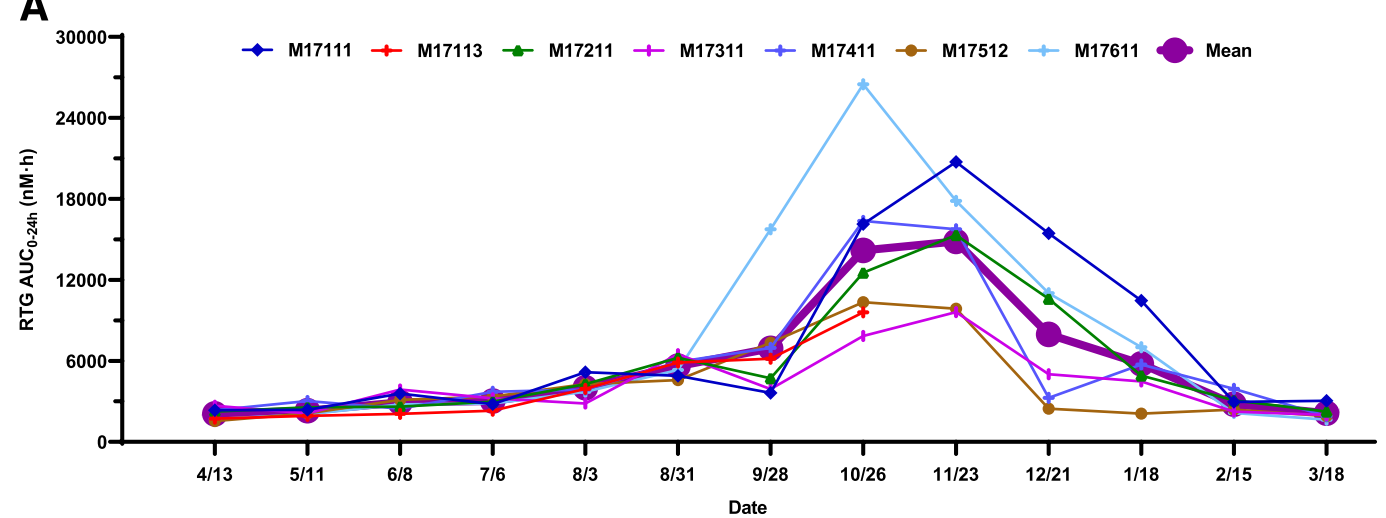

B

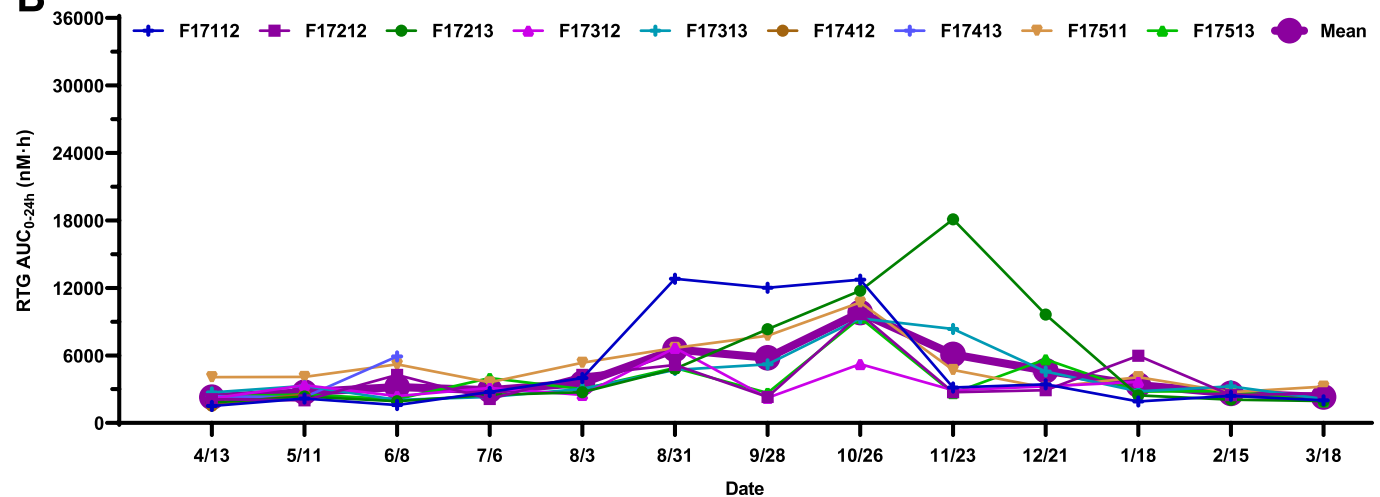

Fig. 4. Individual and mean seasonal $\mathrm{AUC}_{0-24 \mathrm{~h}}$ changes of RTG: (A) male; (B) female. Dates were plotted from April 13, 2017, to March 18, 2018. The AUC $0-24 \mathrm{~h}$ of RTG remained relatively unchanged from April to August and then gradually increased from August to the end of November, reaching the maximum by the end of November and subsequently returning to baseline in March of the following year. A similar trend was observed in female woodchucks, but the peak exposure was reached at the end of October. The exposure increases from May to November in both male and female woodchucks were statistically significant. The magnitude of exposure change was less pronounced in females than in males. Statistical analysis was performed using an unpaired, two-tailed, parametric $t$ test method. Three woodchucks died during the study.

(Fig. 3A). A similar trend was observed in female woodchucks, but the peak exposure was reached at the end of October (Fig. 3B). The exposure increases from May 11 to November 23 in both male (Fig. 7A) and female (Fig. 8A) woodchucks were statistically significant. The magnitude of exposure change was less pronounced in females $(2.1 \pm 2.6$-fold $)$ than in males $(9.0 \pm 4.3$-fold $)$. Although in general no significant sex difference was observed throughout the study duration, a statistically significant seasonal sex difference $(P=$ 0.0011) was observed at the end of November (Fig. 2A and Supplemental Fig. 1A).

The trends of seasonal exposure changes for both RTG and 3TC in male (Fig. 4A; Fig. 5A) and female (Fig. 4B; Fig. 5B) woodchucks were very similar to those corresponding changes for AP (Fig. 3, A and B). Statistically significant increases of RTG and 3TC exposures from May 11 to November 23 were observed in both male (Fig. 7, B and C) and female (Fig. 8, B and C) woodchucks. No significant sex differences in $\mathrm{AUC}_{0-24 \mathrm{~h}}$ values were observed in the year-round study, with the exception that statistically significant seasonal sex differences $(P=$ 0.011 for RTG and $P=0.012$ for 3TC) were observed at the end of November (Fig. 2, B and C, Supplemental Fig. 1, B and C). No significant ICG $\mathrm{AUC}_{0-24 \mathrm{~h}}$ changes were observed in either male (Fig. 6A; Fig. 7D) or female (Fig. 6B; Fig. 8D) woodchucks, and no sex difference was observed (Fig. 2D and Supplemental Fig. 1D) throughout the study duration.

Representative $\mathrm{AUC}_{\mathrm{inf}}, C_{\mathrm{max}}, t_{1 / 2}, \mathrm{~V}_{\mathrm{ss}}$, and $\mathrm{CL}$ values between May 11 and November 23, 2017, were compared in Fig. 9. In both male and female woodchucks, $\mathrm{AUC}_{\mathrm{inf}}$ increases were statistically significant for
AP $(P<0.0001$ for male and $P=0.026$ for female $)$ RTG $(P<0.0001$ for both male and female), and 3TC $(P<0.0001$ for male and $P=$ 0.041 for female) but not for ICG $(P=0.69$ for male and $P=0.77$ for female). No statistically significant $\mathrm{V}_{\text {ss }}$ changes $(P \geq 0.22)$ were observed for any of the four compounds tested in either male or female woodchucks. In both male and female woodchucks, CL decreases were statistically significant for AP $(P<0.0001$ for male and $P=$ 0.0047 for female), RTG $(P<0.0001$ for both male and female), and 3TC ( $P<0.0001$ for male and $P=0.016$ for female $)$ but not for ICG ( $P=0.29$ for male and $P=0.48$ for female). In males, increases of $C_{\max }$ were statistically significant for AP $(P=0.0017)$, RTG $(P<$ $0.0001)$, and 3TC $(P<0.0001)$ but not for ICG $(P=0.68)$. In females, $C_{\max }$ increases were statistically significant for ICG $(P=0.037)$ but not for AP $(P=0.14)$, RTG $(P=0.28)$, or 3TC $(P=0.36)$. In males, increases of $t_{1 / 2}$ were statistically significant for AP $(P<0.0001)$ and 3TC $(P=0.0003)$ but not for RTG $(P=0.061)$ or ICG $(P=0.48)$. In females, $t_{1 / 2}$ increases were statistically significant for $\operatorname{AP}(P=0.039)$ but not for RTG $(P=0.30)$, 3TC $(P=0.14)$ s or ICG $(P=0.70)$. Increased $t_{1 / 2}$ led to a higher percentage of extrapolated $\mathrm{AUC}_{\mathrm{inf}}$ values, which were used to calculate $\mathrm{CL}$ values. As such, seasonal AUC $_{0-24 \mathrm{~h}}$ values were selected as the most representative PK parameters for discussion.

\section{Discussion}

Under wild conditions, it is well known that hibernating animals need to store energy by gaining weight before the winter and slow 

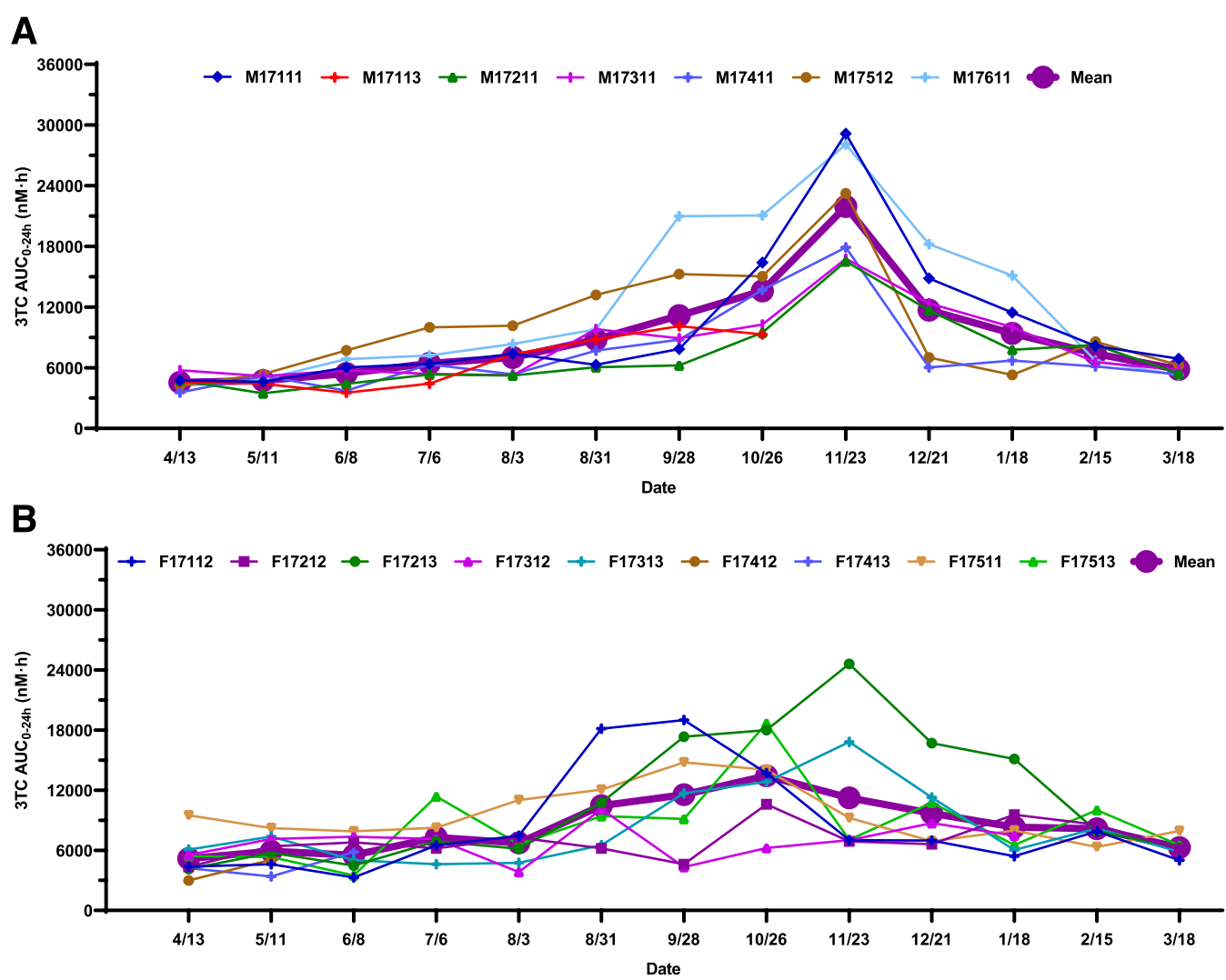

Fig. 5. Individual and mean seasonal $\mathrm{AUC}_{0-24 \mathrm{~h}}$ changes of 3TC: (A) male; (B) female. Dates were plotted from April 13, 2017, to March 18, 2018. The AUC $0-24 \mathrm{~h}$ of 3TC remained relatively unchanged from April to August and then gradually increased from August to the end of November, reaching the maximum by the end of November and subsequently returning to baseline in March of the following year. A similar trend was observed in female woodchucks, but the peak exposure was reached at the end of October. The exposure increases from May to November in both male and female woodchucks were statistically significant. The magnitude of exposure change was less pronounced in females than in males. Statistical analysis was performed using an unpaired, two-tailed, parametric $t$ test method. Three woodchucks died during the study.

their metabolism, lower body temperature, and slow breathing and heart rates during the winter to last through the duration of their dormant period (Geiser, 2004). Reduced cardiac output was reported in 13-lined ground squirrel during hibernation (Bullard and Funkhouser, 1962). Elevated plasma concentrations of persistent organic pollutant and prolonged accumulation of highly reactive metabolites were observed in grizzly bears during hibernation (Christensen et al., 2007). Sex differences in PK were generally attributed to differences in expression of hepatic enzymes (Czerniak, 2001), and hibernating animals such as woodchuck were not typically used as animal models to explore sex differences in toxicology studies (Curry, 2001).

The eastern woodchuck is a hibernating species that is being extensively used in a laboratory setting to study the antiviral efficacy for treatment of chronic HBV infection (Rajagopalan et al., 1996; Genovesi et al., 1998; Mason et al., 1998; Dandri et al., 2000; Korba et al., 2000; Bryant et al., 2001; Menne et al., 2005), functional cure of HBV (Menne et al., 2015; Paulsen et al., 2015; Daffis et al., 2017, 2020), and treatment of WHV-associated hepatocellular carcinoma (Tennant et al., 2004; Iyer et al., 2019).

Under wild conditions, seasonal changes in extrinsic factors, such as light, temperature, and food availability, trigger hibernation (Vybíral and Janský, 1997). Intrinsically, the existence of the trigger substance, i.e., the so-called hibernation induction trigger derived from the blood of hibernating animals, including woodchuck, was reported, and the effect may be species-specific (Vybíral and Janský, 1997). For example, a hibernating-specific $88 \mathrm{kDa}$ protein in the plasma of deeply hibernating woodchucks was described (Horton et al., 1996). Husbandry of woodchucks in a laboratory facility removed the extrinsic factors such as light, temperature, and food availability that can trigger hibernation but is unlikely to alter the intrinsic factors, such as the trigger substance, that led to a pseudohibernation condition.

Under laboratory conditions, the body weight increase from April 12, 2017, to August 14, 2017, was statistically significant for both male and female woodchucks, even though the magnitude of change in males was greater than that in females (Fig. 1A). The higher magnitude of change in body weight for males than females was likely attributed to the reported 38\% higher energy cost for males (Zervanos and Salsbury, 2003). In contrast to wild conditions, no significant changes in body temperature and heart rate were observed throughout the study duration for either male or female woodchucks maintained under laboratory conditions (Fig. 1, B and C). The lack of change in body temperature and heart rate was likely due to woodchucks being kept awake and active under laboratory conditions in contrast to deep hibernation under wild conditions during winter time.

Seasonal plasma $\mathrm{AUC}_{0-24 \mathrm{~h}}$ changes of AP, RTG, and 3TC were used as the markers of change in oxidative metabolism, phase II glucuronidation, or renal clearance in woodchucks, respectively. The significantly higher AP, RTG, and 3TC exposures on November 23, 2017, versus May 11, 2017, indicated that oxidative metabolism, phase II glucuronidation, and renal clearance in woodchuck were significantly reduced during the pseudohibernation. The seasonal sex differences observed at the end of November were mainly due to the magnitude of 
A

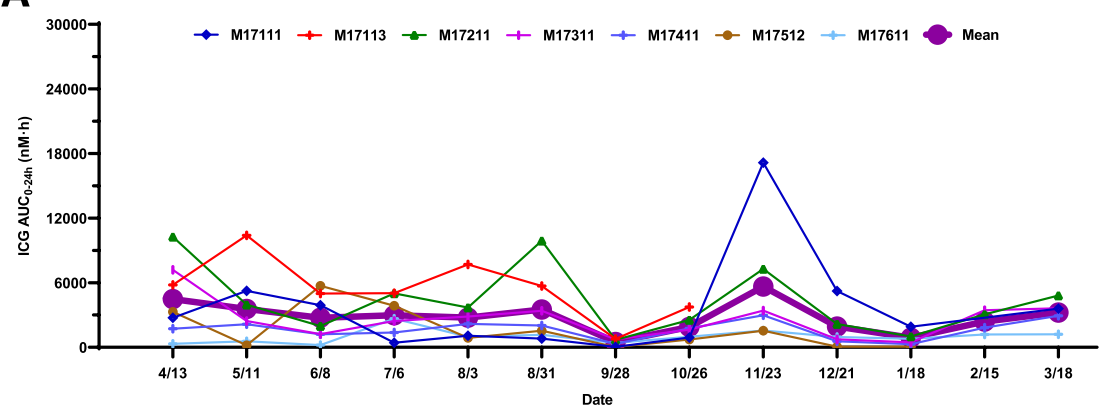

B

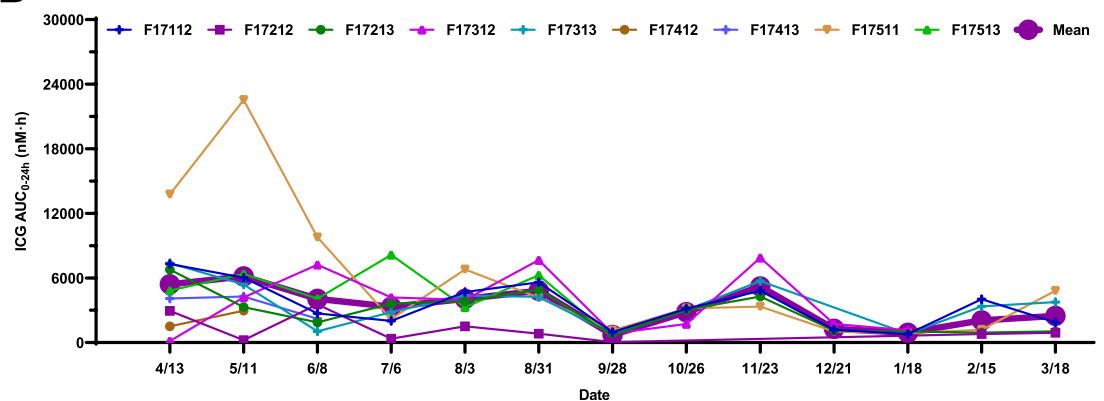

Fig. 6. Individual and mean seasonal $\mathrm{AUC}_{0-24 \mathrm{~h}}$ changes of ICG: (A) male; (B) female. Dates were plotted from April 13, 2017, to March 18, 2018. No significant ICG $\mathrm{AUC}_{0-24 \mathrm{~h}}$ changes were observed in either male or female woodchucks. Statistical analysis was performed using an unpaired, twotailed, parametric $t$ test method. Three woodchucks died during the study. maximum exposure change being less pronounced in females than in males and because the peak exposures were not synchronized between male and female woodchucks.
Seasonal $\mathrm{AUC}_{0-24 \mathrm{~h}}$ of ICG was used as a marker of hepatic function in woodchucks. High variability was observed for ICG $\mathrm{AUC}_{0-24 \mathrm{~h}}$, likely due to a combination of rate of rapid uptake and the
A

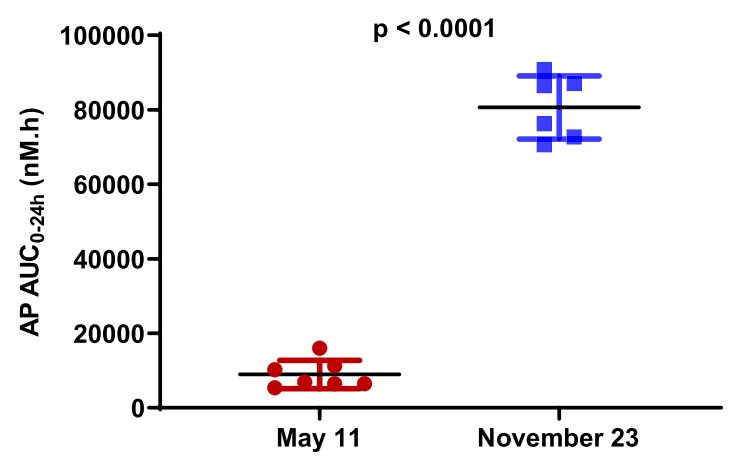

C

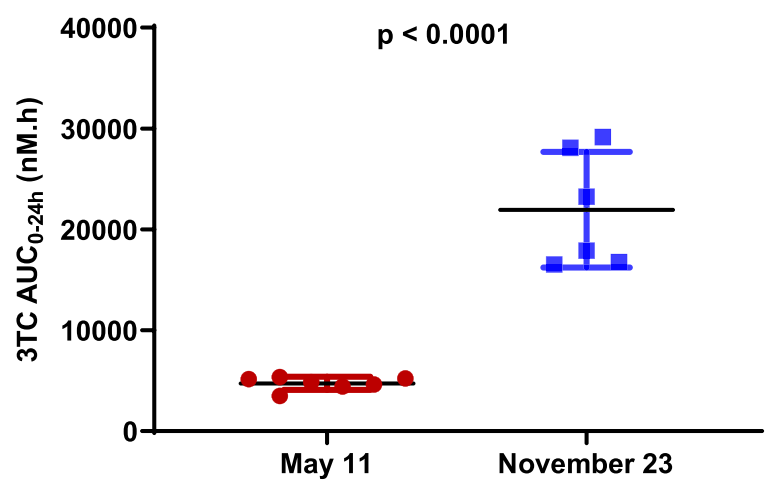

B

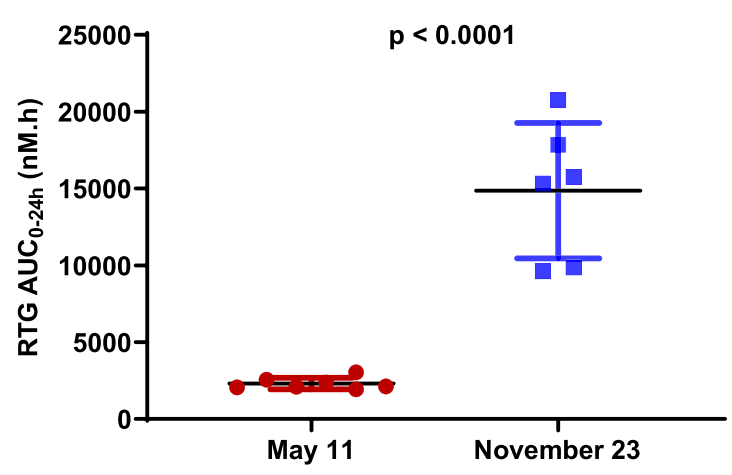

D

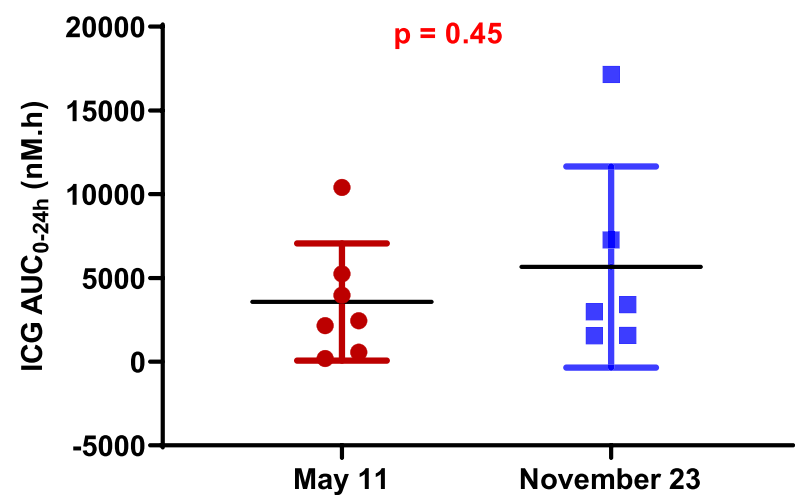

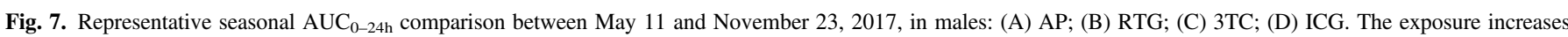

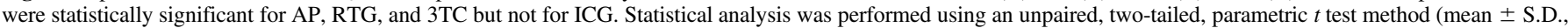
$n=6$ or 7 for male, $n=7$ or 9 for female; three woodchucks died during the study). 
A

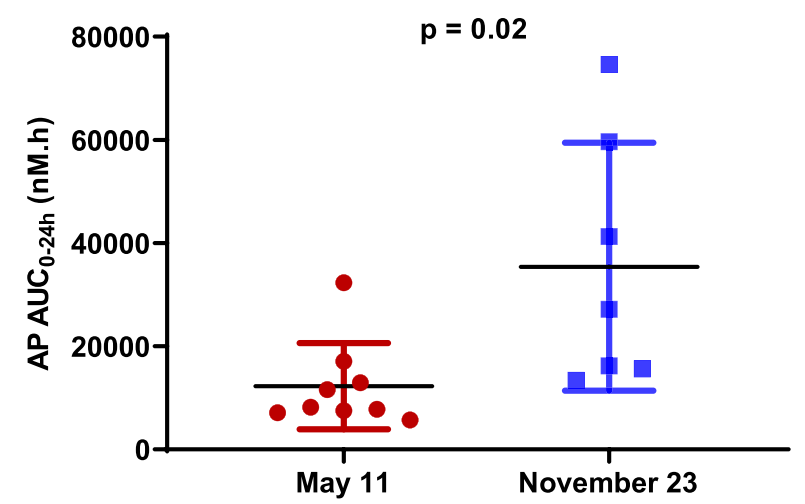

C

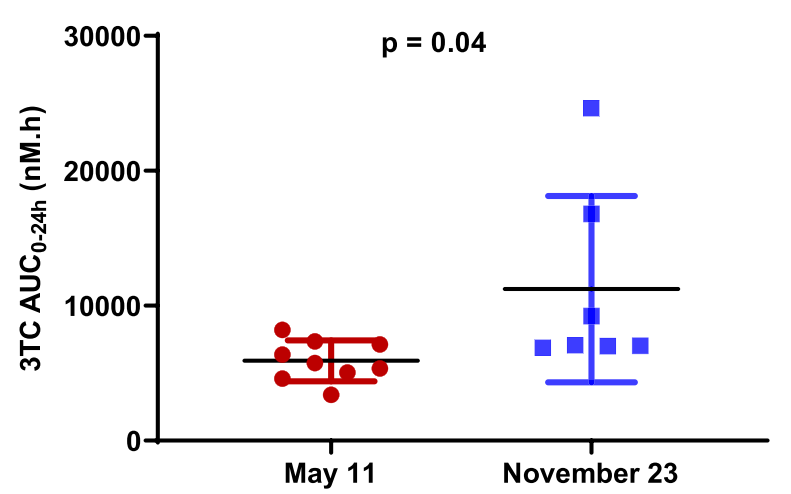

B

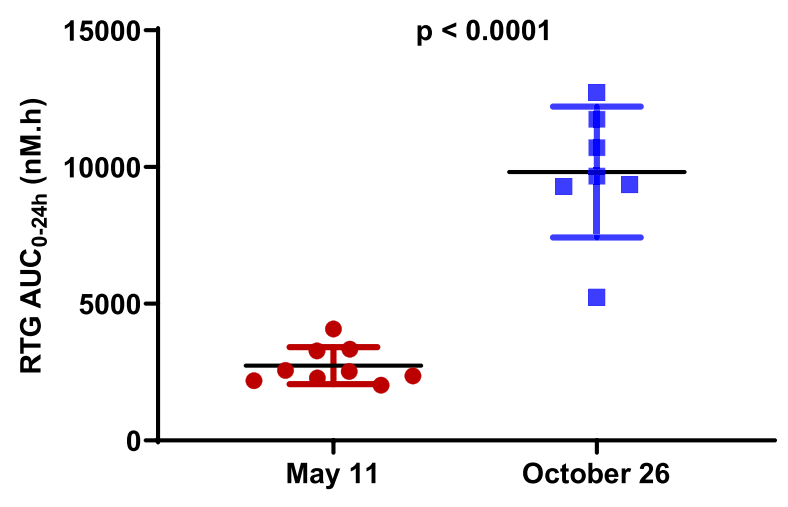

D

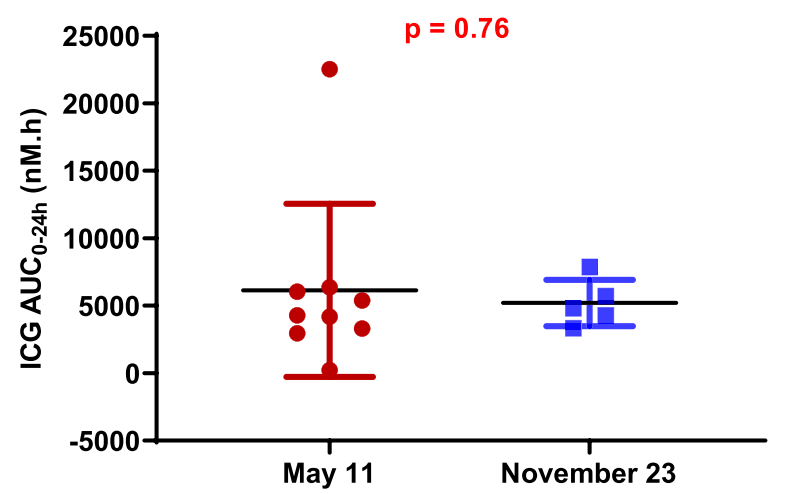

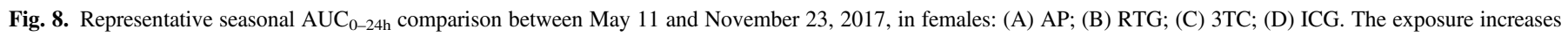

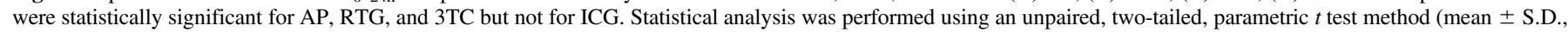
$n=6$ or 7 for male, $n=7$ or 9 for female; three woodchucks died during the study).

precision of time points, even though no protocol violation was reported for sample collection. The lack of change in ICG PK indicated that the hepatic uptake of ICG and blood flow in woodchucks was not significantly altered during the pseudohibernation period.

We acknowledge that the lack of direct evidence, i.e., the amount of 3TC recovered in urine, is a limitation when describing the changes in renal clearance. Caution should also be taken when interpreting these results because drugs chosen to be representative of certain drug disposition processes are based on human knowledge and may not be the same in woodchuck. Another limitation was that sex differences in drug metabolizing enzymes or transporters in woodchucks are not known.

The changes in $\mathrm{AUC}_{\mathrm{inf}}$ and $\mathrm{CL}$ values were consistent with those observed for $\mathrm{AUC}_{0-24 \mathrm{~h}}$. No statistically significant $\mathrm{V}_{\mathrm{ss}}$ changes were observed in either male or female woodchucks. No consistent trends were observed for $C_{\max }$ and $t_{1 / 2}$.

These observed seasonal changes in PK and metabolism could impact how previously published woodchuck PK data are interpreted and understood. Few single-dose woodchuck PK studies reported the study dates. For example, single doses of (-)-P-D-2,6-diaminopurine dioxolane were conducted between October 27 and November 10, which is approximately when indigenous woodchucks would begin winter hibernation (Rajagopalan et al., 1996). Single doses of 1-(2fluoro-5-methyl-b-L-arabinofuranosyl)uracil were conducted between 17 April and June 26, 1996 (Witcher et al., 1997). However, study dates were not reported in many other woodchuck PK studies, particularly for those efficacy studies requiring multiple weeks of treatment-for example, 12-week treatment of adefovir dipivoxil (Cullen et al., 2001); 4-week treatment of tenofovir disoproxil fumarate (Menne et al., 2005); 10-week treatment of MIV-210, a prodrug of 3-fluoro-2,3-dideoxyguanosine (Michalak et al., 2009); and 4- to 8-week treatment of vesatolimod (Menne et al., 2015). In many of these studies, seasonal PK variability was not taken into consideration. Typically, only PK data from prestudy and/or single doses were reported, and these may not be representative of the PK from the efficacy studies. This will make it challenging to compare and reproduce the PK results.

This information can also be used to better plan the long-term woodchuck efficacy studies to not overlap with the pseudohibernation period. Treatment duration in a woodchuck model for HBV typically lasts multiple weeks. If the treatment starts after August or before February, significant change in exposure would be expected given the observed reduction in oxidative metabolism, phase II glucuronidation, and renal clearance in woodchucks during pseudohibernation. The high seasonal PK variability could lead to significant changes in pharmacologic response and potential toxicity.

In summary, seasonal changes were observed in PK and body weight but not body temperature and heart rate in laboratory woodchucks. Significant $\mathrm{AUC}_{0-24 \mathrm{~h}}$ increases for AP, RTG, and 3TC indicated decreases in oxidative metabolism, phase II glucuronidation, and renal clearance during pseudohibernation. The lack of seasonal change in ICG exposure suggested there was no significant change in hepatic function. This information can be used to optimize the scheduling of woodchuck studies to avoid 
A
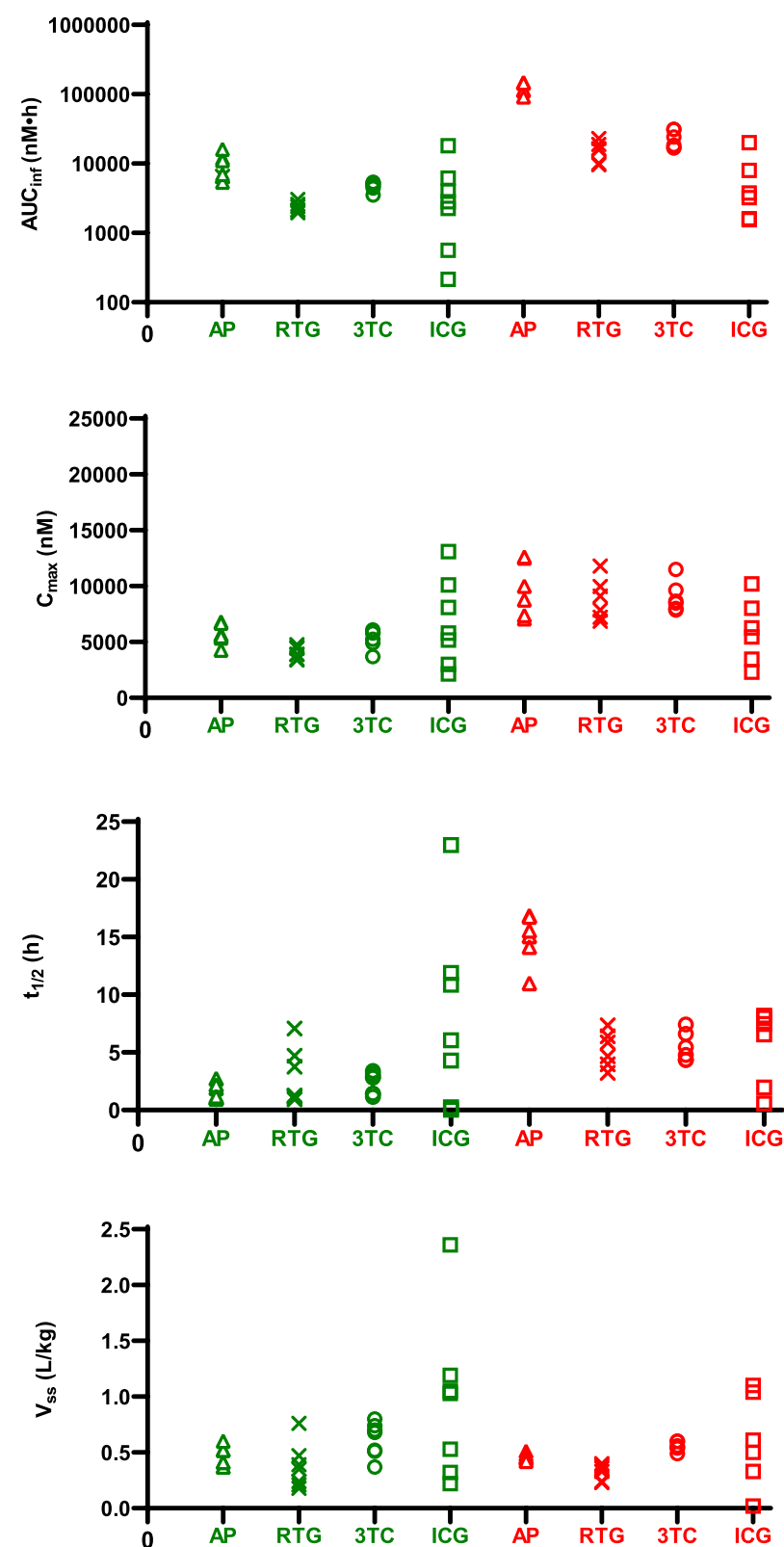

B
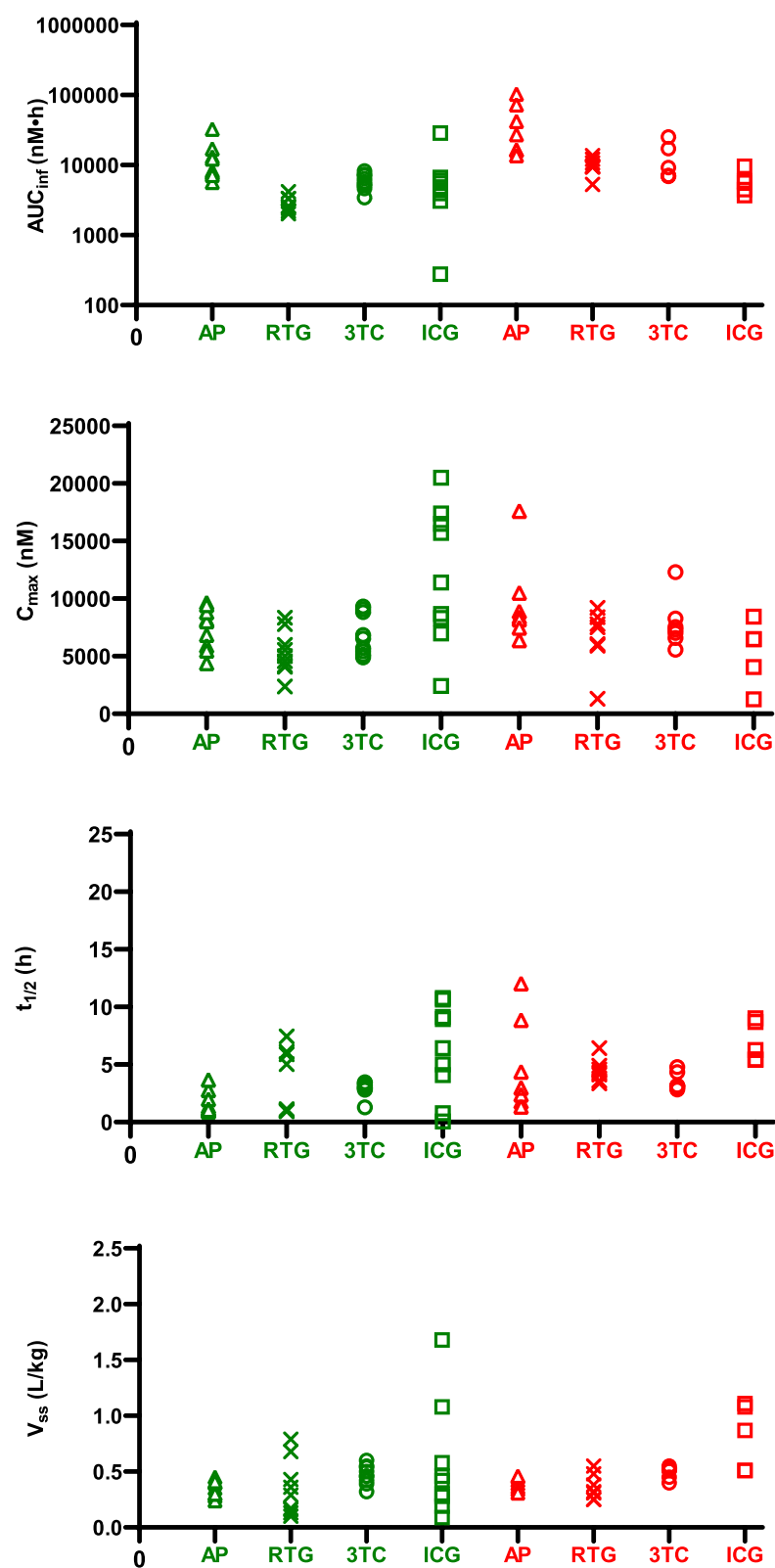

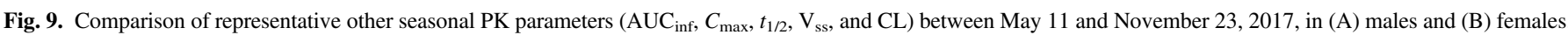

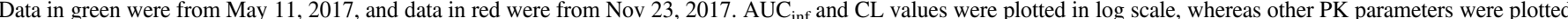

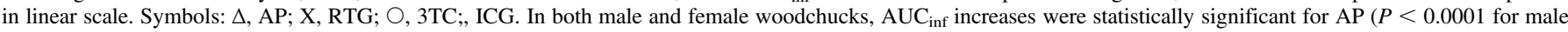

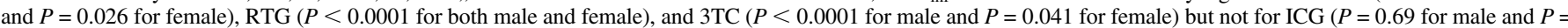

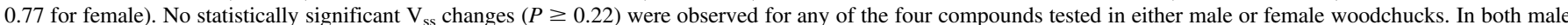

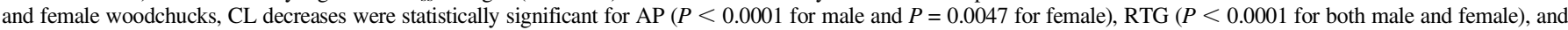

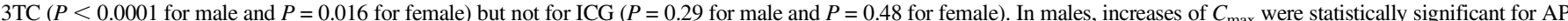

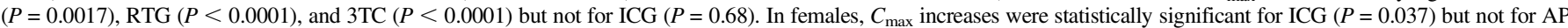

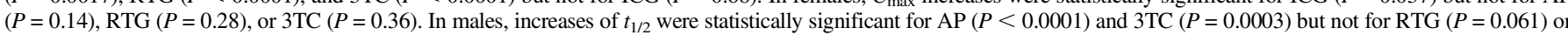

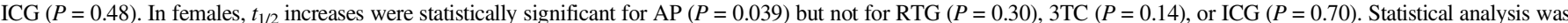
performed using an unpaired, two-tailed, parametric $t$ test method (mean \pm S.D., $n=6$ or 7 for male, $n=7$ or 9 for female; three woodchucks died during the study).

seasonally driven variation in drug PK, pharmacodynamics, and/or toxicity.

\section{Acknowledgments}

We thank Ryan Nguyen and Dr. Robert Strickley for formulation support, Jennifer Tang for editorial assistance using GraphPad Prism, Northeastern Wildlife (Harrison, ID) for conducting the in vivo animal PK studies, and Charles River Laboratories (Worcester, MA) for bioanalytical support.

\section{Authorship Contributions}

Participated in research design: Zheng, Balsitis, Santos, Smith, Subramanian. Performed data analysis: Zheng, Santos.

Wrote or contributed to the writing of the manuscript: Zheng, Balsitis, Santos, Smith, Subramanian.

Note Added in Proof - It was discovered Figure 1B was accidentally duplicated as $1 \mathrm{C}$ in the Fast Forward version of the article published September 5, 2020. Figure $1 \mathrm{C}$ has been corrected. 


\section{References}

Balani SK, Zhu T, Yang TJ, Liu Z, He B, and Lee FW (2002) Effective dosing regimen of 1aminobenzotriazole for inhibition of antipyrine clearance in rats, dogs, and monkeys. Drug Metab Dispos 30:1059-1062.

Bryant ML, Bridges EG, Placidi L, Faraj A, Loi AG, Pierra C, Dukhan D, Gosselin G, Imbach JL, Hernandez B, et al. (2001) Antiviral L-nucleosides specific for hepatitis B virus infection. Antimicrob Agents Chemother 45:229-235.

Bullard RW and Funkhouser GE (1962) Estimated regional blood flow by rubidium 86 distribution during arousal from hibernation. Am J Physiol 203:266-270.

Christensen JR, MacDuffee M, Yunker MB, and Ross PS (2007) Hibernation-associated changes in persistent organic pollutant (POP) levels and patterns in British Columbia grizzly bears (ursus arctos horribilis). Environ Sci Technol 41:1834-1840.

Cooke AR, Harrison DD, and Skyring AP (1963) Use of indocyanine green as a test of liver function. Am J Dig Dis 8:244-250.

Cullen JM, Li DH, Brown C, Eisenberg EJ, Cundy KC, Wolfe J, Toole J, and Gibbs C (2001) Antiviral efficacy and pharmacokinetics of oral adefovir dipivoxil in chronically woodchuck hepatitis virus-infected woodchucks. Antimicrob Agents Chemother 45:2740-2745.

Curry BB III (2001) Animal models used in identifying gender-related differences. Int J Toxicol 20: $153-160$.

Czerniak R (2001) Gender-based differences in pharmacokinetics in laboratory animal models. Int J Toxicol 20:161-163.

Daffis S, Balsitis S, Chamberlain J, Zheng J, Santos R, Rowe W, Ramakrishnan D, Pattabiraman D, Spurlock S, Chu R, et al. (2020) Toll-like receptor 8 agonist GS-9688 induces sustained efficacy in the woodchuck model of chronic hepatitis B. Hepatology DOI: 10.1002/hep.31255 [published ahead of print].

Daffis S, Chamberlain J, Zheng J, Santos R, Rowe W, Mish M, Ramakrishnan D, Yon C, Suresh M, Menne S, et al. (2017) Sustained efficacy and surface antigen seroconversion in the woodchuck model of chronic hepatitis B with the selective toll-like receptor 8 agonist GS-9688, in Int Liver Congress, pp Poster SAT-165; Amsterdam, The Netherlands.

Dandri M, Burda MR, Will H, and Petersen J (2000) Increased hepatocyte turnover and inhibition of woodchuck hepatitis B virus replication by adefovir in vitro do not lead to reduction of the closed circular DNA. Hepatology 32:139-146.

Dandri M and Petersen J (2017) Animal models of HBV infection. Best Pract Res Clin Gastroenterol 31:273-279.

de Graaf W, Häusler S, Heger M, van Ginhoven TM, van Cappellen G, Bennink RJ, Kullak-Ublick GA, Hesselmann R, van Gulik TM, and Stieger B (2011) Transporters involved in the hepatic uptake of (99m)Tc-mebrofenin and indocyanine green. J Hepatol 54:738-745.

Geiser F (2004) Metabolic rate and body temperature reduction during hibernation and daily torpor Апnи Rev Physiol 66:239-274.

Genovesi EV, Lamb L, Medina I, Taylor D, Seifer M, Innaimo S, Colonno RJ, Standring DN, and Clark JM (1998) Efficacy of the carbocyclic 2'-deoxyguanosine nucleoside BMS-200475 in the woodchuck model of hepatitis B virus infection. Antimicrob Agents Chemother 42 : 3209-3217.

Hong SK (1957) Renal function during hypothermia and hibernation. Am J Physiol 188:137-150.

Horton ND, Oeltgen PR, Kaftani DJ, Su T-P, Bruce DS, Krober AS, and Jones JF (1996) Biochemical Characterization of a Hibernation-specific $88 \mathrm{kDa}$ Protein Derived from the Plasma of Deeply Hibernating Woodchucks, University of New England Press, Armidale, NSW.

Huang L and Vore M (2001) Multidrug resistance p-glycoprotein 2 is essential for the biliary excretion of indocyanine green. Drug Metab Dispos 29:634-637.

Hwang Y, Yoon H, Choe K, Ahn J, Jung JH, Park J-H, and Kim P (2017) In vivo cellular-level real-time pharmacokinetic imaging of free-form and liposomal indocyanine green in liver. Biomed Opt Express 8:4706-4716.

Iyer RV, Maguire O, Kim M, Curtin LI, Sexton S, Fisher DT, Schihl SA, Fetterly G, Menne S, and Minderman H (2019) Dose-dependent sorafenib-induced immunosuppression is associated with aberrant NFAT activation and expression of PD-1 in T cells. Cancers (Basel) 11 : 681.

Johnson MA, Moore KH, Yuen GJ, Bye A, and Pakes GE (1999) Clinical pharmacokinetics of lamivudine. Clin Pharmacokinet 36:41-66.

Kassahun K, McIntosh I, Cui D, Hreniuk D, Merschman S, Lasseter K, Azrolan N, Iwamoto M, Wagner JA, and Wenning LA (2007) Metabolism and disposition in humans of raltegravir
(MK-0518), an anti-AIDS drug targeting the human immunodeficiency virus 1 integrase enzyme. Drug Metab Dispos 35:1657-1663.

Korba BE, Cote P, Hornbuckle W, Tennant BC, and Gerin JL (2000) Treatment of chronic woodchuck hepatitis virus infection in the Eastern woodchuck (Marmota monax) with nucleoside analogues is predictive of therapy for chronic hepatitis B virus infection in humans. Hepatology 31:1165-1175.

Liu SN, Lu JBL, Watson CJW, Lazarus P, Desta Z, and Gufford BT (2019) Mechanistic assessment of extrahepatic contributions to glucuronidation of integrase strand transfer inhibitors. Drug Metab Dispos 47:535-544.

Mackman Richard L, Mish Michael, Chin Gregory, Perry Jason K, Appleby Todd, Aktoudianakis Vangelis, Metobo Sammy, Pyun Peter, Niu Congrong, Daffis Stephane, et al. (2020) Discovery of GS-9688 (Selgantolimod) as a Potent and Selective Oral Toll-Like Receptor 8 Agonist for the Treatment of Chronic Hepatitis B. J Med Chem 63 (18):10188-10203, doi: 10.1021/acs.jmedchem.0c00100 32407112.

Mason WS, Cullen J, Moraleda G, Saputelli J, Aldrich CE, Miller DS, Tennant B, Frick L, Averett D, Condreay LD, et al. (1998) Lamivudine therapy of WHV-infected woodchucks. Virology 245:18-32.

Menne S and Cote PJ (2007) The woodchuck as an animal model for pathogenesis and therapy of chronic hepatitis B virus infection. World J Gastroenterol 13:104-124.

Menne S, Cote PJ, Korba BE, Butler SD, George AL, Tochkov IA, Delaney WE IV, Xiong S, Gerin JL, and Tennant BC (2005) Antiviral effect of oral administration of tenofovir disoproxil fumarate in woodchucks with chronic woodchuck hepatitis virus infection. Antimicrob Agents Chemother 49:2720-2728.

Menne S, Tumas DB, Liu KH, Thampi L, AlDeghaither D, Baldwin BH, Bellezza CA, Cote PJ, Zheng J, Halcomb R, et al. (2015) Sustained efficacy and seroconversion with the Toll-like receptor 7 agonist GS-9620 in the Woodchuck model of chronic hepatitis B. J Hepatol 62: $1237-1245$.

Michalak TI, Zhang H, Churchill ND, Larsson T, Johansson N-G, and Öberg B (2009) Profound antiviral effect of oral administration of MIV-210 on chronic hepadnaviral infection in a woodchuck model of hepatitis B. Antimicrob Agents Chemother 53:3803-3814.

Mulawa EA, Kirkwood JS, Wolfe LM, Wojda SJ, Prenni JE, Florant GL, and Donahue SW (2018) Seasonal changes in endocannabinoid concentrations between active and hibernating marmots (marmota flaviventris). J Biol Rhythms 33:388-401.

Paulsen D, Weber O, Ruebsamen-Schaeff H, Tennant BC, and Menne S (2015) AIC649 induces a bi-phasic treatment response in the woodchuck model of chronic hepatitis B. PLoS One 10: e0144383.

Rajagopalan P, Boudinot FD, Chu CK, Tennant BC, Baldwin BH, and Schinazi RF (1996) Pharmacokinetics of (-)-2'-3'-dideoxy-3'-thiacytidine in woodchucks. Antimicrob Agents Chemother 40:642-645.

Roggendorf M and Tolle TK (1995) The woodchuck: an animal model for hepatitis B virus infection in man. Intervirology 38:100-112.

Tennant BC, Toshkov IA, Peek SF, Jacob JR, Menne S, Hornbuckle WE, Schinazi RD, Korba BE, Cote PJ, and Gerin JL (2004) Hepatocellular carcinoma in the woodchuck model of hepatitis B virus infection. Gastroenterology 127 (5 Suppl 1):S283-S293.

Vybíral S and Janský L (1997) Hibernation triggers and cryogens: do they play a role in hibernation? Comp Biochem Physiol A Physiol 118:1125-1133.

Witcher JW, Boudinot FD, Baldwin BH, Ascenzi MA, Tennant BC, Du JF, and Chu CK (1997) Pharmacokinetics of 1-(2-fluoro-5-methyl-beta-L-arabinofuranosyl)uracil in woodchucks. Antimicrob Agents Chemother 41:2184-2187.

Zatzman ML and South FE (1972) Renal function of the awake and hibernating marmot Marmota flaviventris. Am J Physiol 222:1035-1039.

Zatzman ML and Thornhill GV (1989) Plasma levels of atrial natriuretic factor in nonhibernating and hibernating marmots. Cryobiology 26:196-198.

Zervanos SM and Salsbury CM (2003) Seasonal body temperature fluctuations and energetic strategies in free-ranging eastern woodchucks (Marmota monax). J Mammal 84:299-310.

Address correspondence to: Dr. Jim Zheng, Gilead Sciences, Inc., 333 Lakeside Dr, Foster City, CA 94404. E-mail: Jim.Zheng@gilead.com 